\title{
A Model for Teaching Basic Engineering Statistics in Slovenia
}

\author{
Andreja Drobnič Vidic ${ }^{1}$
}

\begin{abstract}
Statistics contents are commonly included in university curricula. Slovenian students in general have a lack of problem solving and application knowledge in mathematics and basic statistics. Moreover, engineering students have a lack of teamwork skills, needed in their professional careers. In order to reduce these shortcomings we designed a model for teaching basic statistics to engineering students. The problembased learning (PBL) approach served as the basis for this model. We adapted it to the requirements of a basic engineering statistics course and to the environment of a Slovenian university. Four main factors of the model are described in detail: problems, which enable the development of problem solving skills and application of knowledge; PBL teachers, who need to change their roles and activities in the instruction; aims of the students, and the alternative assessment. The article also makes reference to a pedagogical experiment, in which we verified this model.
\end{abstract}

\section{Introduction}

In Slovenia, the teachers of statistics at high schools and at universities are often non-statistics experts. Teachers of this professional profile teach statistics to around $80 \%$ of students taking one of the higher education programmes. Many of them have a low level of application of statistical knowledge and a weak problem solving competence. This situation is a result of the traditional curriculum design in secondary schools and universities, which is also reflected in poor interdisciplinary cooperation and in failure to integrate knowledge from different science domains.

The problem-based learning approach integrated in the traditional curriculum seemed particularly well adapted to teaching basic statistics to students in higher education programmes. Therefore, we designed a PBL model for the purposes of teaching statistics to engineering students. After the description of PBL

\footnotetext{
1 Andreja Drobnič Vidic, Faculty of Mathematics and Physics, Jadranska 19, SI-1000 Ljubljana, Slovenia, andreja.drobnic@fmf.uni-lj.si, andreja.drobnic@fkkt.uni-lj.si.
} 
characteristics and advantages for using PBL in basic statistics for engineers the four most important factors for the model are described in more detail. The article also makes reference to a pedagogical experiment, in which we verified this model.

\section{Basic statistics course in Slovenia}

Statistics is a relatively young, but rapidly growing science, as it is used for different purposes, in connection with different disciplines. Therefore teaching statistics is an extremely complex and demanding task. This is especially true for those teachers of mathematics who are not experts in statistics. In Slovenia, many teachers of the basic statistics course in secondary schools and universities are not statisticians. Before study year 2002/03 Slovenia did not have any study programmes of statistics. Therefore, teachers of basic statistics courses have to gain knowledge by self-learning or by helping each other to promote good statistics teaching strategies. While data management, basic processing and data display seem to be less problematic, students at university level often find it difficult to understand statistics through the theory of probability calculation. Practical real data are difficult to relate to a theory based on mathematical derivation and theoretical distributions.

Teaching statistics is a delicate job in other countries, too (Cobb, 1993). We can find an extensive literature about this particular field. Many authors in Proceedings of teaching statistics ICOTS5 (Mendoza, 1998) or Journal of statistics education, for instance, have pointed to useful statistics teaching methods, focused around one of the following features:

- teaching statistics through concrete real-life cases (Moore and McCabe, 2003; Wood and Wasimi, 1998),

- teaching statistics with computer programs (Rossman et al., 2002),

- cooperative learning with group work (Garfield, 1993; Magel, 1998), or

- active learning with experiments (Scheaffer et al., 1996).

Typically, a "basic statistics course" at university contains a general overview of basic statistics: from collection of data and information, sampling and calculation of basic statistical parameters to devising statistical hypotheses. At University of Ljubljana (UL) there are around three quarters of students with a basic statistics course in their university curriculum. According to our survey (Drobnič Vidic, 2003), $70 \%$ of students, registered as first-year students at UL in 2001/02, had a course in basic statistics in their university curriculum. From among all regular and part-time students in higher professional education study programmes at UL, $81 \%$ of students, registered as first year students in 2001/02, had a basic statistics course in their university curriculum. From among all part- 
time students in higher professional education study programmes at UL, $97 \%$ of students, registered as first year students in 2001/02, had a basic statistics course in their university curriculum. Therefore, it may be concluded that the study programmes which are closer to professional fields more frequently require basic statistical knowledge. In this article, we are focusing on a teaching strategy for a basic engineering statistics course in Slovenia. A so - called "basic engineering statistics course" is offered to students in higher professional education study programmes aimed at future engineers in different fields, such as geodesy, mining, computer and information science, safety, practical mathematics, civil engineering, etc.

Slovenia participated in TIMSS international research 1995 and 1999. This participation yielded a comparative analysis of mathematic and statistic competences (the latter constituting an integral part of mathematics in secondary school curricula) in the Slovene secondary school population as compared to the secondary school population worldwide. The analyses pointed to two main weaknesses of the Slovene secondary school population, namely a low level of application of (statistical) knowledge and weak problem solving competence (Japelj et al., 2002; Drobnič Vidic, 2003). This situation is a result of a traditional curriculum design in secondary schools and universities, which is also reflected in poor interdisciplinary cooperation and in failure to integrate knowledge from different science domains.

On the other hand, corporations and employers have frequently and publicly complained about the lack of professional awareness and low level of communication and teamwork skills in engineering graduates. Numerous surveys and industry assessments place communication and teamwork at the top of their list of desirable skills for new engineering graduates, because most of engineering is done cooperatively (Garfield, 1993). Students who have experienced cooperative learning tend to have more highly developed critical thinking and problem solving skills, a lower level of anxiety, and better and longer information retention. Moreover, engineers are called on to absorb vast amounts of information that is increasing more rapidly than the ability of the engineering curricula to cover it.

An innovation from the last few decades, called problem-based learning (PBL), seemed to be particularly adapted to teaching basic statistics to engineering students in higher education programmes. This approach enables a higher applicability of knowledge, it enhances problem-solving competences and combines most of the previously mentioned features used in statistics teaching and learning. Consequently, we designed a PBL model for the purposes of teaching basic statistics to engineering students. 


\section{Problem-based learning}

Problem-based learning (PBL) is an instructional approach in which a problem takes the central role in the learning process and constitutes the motivation for the student's activities. Boud and Feletti (1998) consider the PBL as one of the most influential innovations of the last decades and define it as a carefully planned curriculum, which is entirely based on practical cases and on solving practical problems. PBL offers an environment in which learning is triggered and guided by a problem. This means that students are confronted with a problem prior to the acquisition of new knowledge.

PBL first appeared in different medical faculties (McMaster University in Canada, the Medical School of Maastricht University in the Netherlands) (David et al., 1999: 2-3). Later on, it spread to different disciplines, such as law, economy, psychology, chemical engineering, architecture, etc (Woods, 1994: preface; Eitel and Gijselaers, 1997). One of the basic characteristics of PBL is that it trains students to become better able to work in a group of experts. It also enhances cooperative problem solving related to typical situations of the student's expert field, e.g. medicine.

PBL is mainly characterised by the following features:

1. PBL is a way of organising instruction by focusing on a problem as a motivation for the student's activities. The problem should be professionally relevant and as close as possible to real-life situations. Moreover, it should be ill structured, complex and designed in such a way that the students cannot simply solve it by using their prior knowledge. It should be perceived as interesting by the students. Problem-solving activities enhance the development of cognitive methods and critical thinking. In order to be able to solve the problem, students must gain new knowledge corresponding to the definition of educational objectives of the curriculum. As the focus is shifted to the PBL situation, the choice of adequate problems becomes very important (Schmidt and Moust, 1998; Schmidt and Moust, 2000; Gijselaers and Schmidt, 1990; Dolmans and SnellenBalendong, 2000).

2. Students usually solve problems in small groups (4-15 students), where cooperative learning is encouraged. Students are also stimulated to search for new information, and solve a part of a given problem as independent learners. They are assisted by a tutor, who is acquainted with the field, but need not necessarily be a teacher. The tutor guides the learning process. The problem-solving usually follows a 7 Steps Model (Table 1):

3. Learning in a group according to the 7 Steps Model enables a constructivist knowledge acquisition (Hendry, Frommer, and Walker, 1999). At the beginning of the problem-solving cycle the students should draw on their prior knowledge, whereby possible ways of problem solving and the gaps in knowledge are determined. It is often claimed that the PBL derives from the premises of 
constructivism (Hendry, Frommer, and Walker, 1999) and that this learning method is based on constructivist principles. It is important for the students to integrate new knowledge in their own cognitive structures so as to establish a connection with the prior information. Thus the gained knowledge can be used in new situations. All these processes are stimulated by group discussion and immediate feedback information on the level of knowledge acquisition.

Table 1: Problem-solving according to the 7 Steps Model (Moust et al., 2001: 30).

\begin{tabular}{|c|c|c|}
\hline No & The 7 Steps Model & Meetings \\
\hline 1 & Clarification of unclear terminology and concepts & \multirow{5}{*}{$\begin{array}{c}\text { Meeting } \\
1: \\
\text { Goals }\end{array}$} \\
\hline 2 & Definition of the problem & \\
\hline 3 & Analysis of the problem (brainstorming) & \\
\hline 4 & List of possible explanations & \\
\hline 5 & Formulation of learning aims and key tasks & \\
\hline 6 & $\begin{array}{l}\text { Independent search for additional information outside the } \\
\text { group }\end{array}$ & \multirow{2}{*}{$\begin{array}{c}\text { Meeting } \\
2: \\
\text { Learning }\end{array}$} \\
\hline 7 & Report, synthesis and testing of the new information & \\
\hline
\end{tabular}

4. The teacher is no longer a lecturer and the only source of knowledge, since the students do not get information directly from him / her. The teacher is a facilitator, who assists the students in the skills acquisition process and develops the students' independent-learning capacities (Wilkerson and Hundert, 1998; Vermunt and Verloop, 1999). The classical lecturing can play only a supportive role in the process. Teachers should be acquainted with the level of the students' prior knowledge and should help activate this knowledge. Facilitators should be dynamic, able to adapt the learning materials to the innovations in the education field as well as capable of integrating the theory with the practice.

5. PBL is a student-centred method of learning (Cannon and Newble, 2000). Students are trained for independent learning. This feature facilitates lifelong learning. In student-centred learning the students become responsible for their own work and do not have the feeling that learning was imposed on them. The quality of the gained knowledge is much more important than the transfer of the knowledge from the teacher to the student. Students as well as teachers should move from the "teaching paradigm" to the "learning paradigm" (Barr and Tagg, 1995).

6. PBL offers the possibility to develop other competences and skills (Moust, Bouhuijs, and Schmidt, 2001: 13): problem-solving skills, skills required for effective group work and independent learning. Woods (1994: 2-3) studied also the self-assessment skills, where the students critically evaluate their individual work and progress as well as the work carried out by the whole group. All these skills are important for effective independent learning. 
7. The teacher must change assessment methods if he or she wants the students to follow the main goals set by the PBL approach. It is, in fact, the assessment system which dictates learning and work carried out by students (Driessen and Van der Vleuten, 2000). If the teacher does not assess an item the students will not learn it (Lovie-Kitchin, 2001: 149-155). Therefore assessment in PBL is at least as important as curriculum design. In PBL the acquired knowledge and the student's ability to solve real-life problems are assessed rather than the student's test writing skills. Assessment is usually composed of different elements: the tutor's grade is complemented by self-assessment and peer-assessment grades. A very important function of assessment is to give the student immediate feedback information on whether his /her learning process is adequate, whether the expected development is achieved and whether a certain knowledge or skill needs to be improved. At the beginning of the PBL the students should be acquainted with the kind of knowledge and skills which are going to be assessed.

The PBL should stretch over a fixed period of time (a semester, an academic year, a course, or an integral part of course content). All these changes in PBL prove to be particularly productive with students who are sufficiently mature and who have been involved in the education process for a longer period of time.

\section{PBL as a useful teaching strategy for a basic engineering statistics course}

The PBL is less used in natural sciences than in other sciences, such as medicine, law (Perrenet, Bouhuijs and Smits, 2000), even though the constructivist approach is very important for the natural sciences (Staver, 1998). Within the subject of statistics, the PBL is applied at faculties, which have adopted the PBL approach at the institutional level. At University of Samford in Alabama, USA, the statistics course is integrated in a PBL faculty curriculum for future medical doctors and nurses (http://www.samford.edu/pbl/PBL2000/stats.htm). The Illinois Mathematics and Science Academy is positioned as a leader in PBL with its national / international reputation as a provider of PBL training at the K-12 levels and beyond. The IMSA's institutes (http://www2.imsa.edu/programs/pbln/) provide a practical framework to enable classroom teachers to implement these theoretical beliefs. Bland (2004) describes how the statistics course is integrated in a PBL curriculum of medical studies in Australia. An interesting biostatistics course with PBL is introduced at Mississippi University (Boyle, 1999). We can also find some PBL courses with the advanced levels of studies, where an in-depth knowledge of statistics is required (Fillebrown, 1994; Mackisack, 1994).

Teaching basic statistics for engineers and PBL have a lot in common. One of the main objectives of the use of statistics in the engineering field is to solve problems from the chosen field of study. In PBL, problems have a central role. 
Learning statistics implies understanding and acquiring mathematical knowledge, which is reflected in the understanding of different statistic principles and statistic testing methods. It can be observed with the students of engineering that these principles and methods are often learned or understood in an inadequate way. Group work and exchange of opinions within the PBL enable early detection of mistakes and misconceptions in knowledge. Prior to their enrolment, the students have been - at least to some degree - acquainted with the basic statistics through their everyday life experience, which helps them build new knowledge according to constructivist principles. That is why the PBL is believed to be particularly suitable in teaching basic engineering statistics.

Statistics constitutes a link between mathematics, information and communication technology (ICT) and different disciplines, as well as with foreign language competences, which are necessary to keep abreast of the latest developments in specialised literature. With its large spectrum of application, statistics offers the possibility to choose different problems, which enhance learning of the same content. PBL with real complex problems demands an interdisciplinary approach to learning.

Statistical problems for engineers are often difficult to solve for a single student, because the problem-solving involves a lot of different activities ranging from data collection, data management, sometimes even measurement, computer processing, devising statistical hypotheses and display of the interpretation of results. These activities require teamwork and use of the computer, which are important components in PBL, too. In PBL it is important that students don't learn from one textbook, they should use different sources and modern technology. In the time of expansion of knowledge young people have to learn how to search effectively for the relevant information, how to critically select it and adopt the most efficient learning strategies. This is also one of the aims of the instruction in the field of statistics and of PBL.

To target these aims we designed a PBL based model for teaching the basic engineering statistics. The model is integrated in the traditional curriculum, however it merges different subjects: ICT, basic engineering statistics and some segments of particular fields. It is adapted to the situation at the University of Ljubljana, which has the largest number of students in Slovenia and is characterised by: poor ICT equipment, lack of tutors, and large groups of students.

\section{$5 \quad$ PBL model for teaching basic engineering statistics}

PBL usually requires a special problem-based curriculum (Snellen-Balendong, 1993; Colliver, 2000). This, however, is not a necessary precondition in our case, since basic engineering statistics course and PBL have much in common. It is therefore possible to incorporate a PBL approach in the traditional curriculum. 
Table 2: Why PBL is suitable for a basic statistics course.

\begin{tabular}{|c|c|}
\hline STATISTICS & PBL \\
\hline $\begin{array}{l}\text { One of the main objectives of the use of } \\
\text { statistics is to solve problems from a } \\
\text { chosen field of study. }\end{array}$ & $\begin{array}{c}\text { In PBL, problem solving has a central } \\
\text { role. }\end{array}$ \\
\hline $\begin{array}{l}\text { Statistical problems dismantle the neat } \\
\text { lines between disciplines. }\end{array}$ & $\begin{array}{l}\text { PBL with real complex problems } \\
\text { connects different disciplines. }\end{array}$ \\
\hline $\begin{array}{c}\text { Computer is a very important and useful } \\
\text { tool in statistics. }\end{array}$ & $\begin{array}{l}\text { PBL requires IT and other sources for } \\
\text { the acquisition of new information. }\end{array}$ \\
\hline $\begin{array}{c}\text { Statistical engineering problems involve } \\
\text { a lot of activities - they require } \\
\text { teamwork. }\end{array}$ & Students in PBL work in small groups. \\
\hline $\begin{array}{l}\text { Learning statistics requires } \\
\text { mathematical knowledge: learning with } \\
\text { understanding. }\end{array}$ & $\begin{array}{l}\text { PBL students build new knowledge } \\
\text { according to constructivist principles. }\end{array}$ \\
\hline
\end{tabular}

The basic engineering statistics course in a PBL model consists of "problem" phases. Each phase contains 2 - 4 meetings with group problem solving. During the first meeting students can work on the first five steps of the 7 Steps Model. The aim of the meeting is to clarify the objectives for self-study. Then they work independently at home, looking for new information. During the second meeting students sum up new information and knowledge, try to make a synthesis and solve the problem. Here is a sample problem designed for our course in the introductory phase:

The number of reservations for American Air. American Air Flight 2705 from New York to Boston has seats for 120 passengers. Usually every passenger reserves a seat in advance. Because this particular line is very busy, usually all the seats are reserved. Someone who reserves a seat, can show up or not. An average of $5 \%$ of people with reservations doesn't show up, so American Air overbooks by accepting 126 reservations for the 120 seats. Explain. (Triola, 2001: 236; Drobnič Vidic, 2005: 141).

During the first meeting students should clarify unknown terms if any (1). They try to explain the nature of the problem in their own words, for instance: "We need to find out, why American Air booked exactly 126 instead of 120 seats?"(2). They may search for the solution by making guesses about the reasons for the agency's policy (they try to connect the problem with their previous knowledge - probability calculations, random variables) (3). After that they write down some facts, which can be calculated from the data given. They should conclude that there is a probability of $95 \%$ that a person who reserves a seat also comes on the plane and a $5 \%$ probability that a person doesn't come on the plane. With each reservation of the seat there are exactly two possibilities; the person may show up or not. Students might calculate the probability that among all 120 reservations exactly 1 person doesn't show up. They might do the same calculation for exactly 2 persons $(3,4$ persons, etc.) not showing up. Computer assisted calculation is a good option at this point (4). Students should set up the following objectives: make a table of all possible issues with probabilities (distribution schema), define the random 
variable connecting to this schema, find its mean, variance, etc. (5). They should conclude that they have to deal with binomial distribution. A facilitator has an important role to play: he / she asks questions, making sure the students are on the right track or helping them retrieve some prior knowledge about distributions and so on. At home students should read about binomial distribution and find out some interesting features (6). At the next meeting, they find out that 6 is the mean for binomial variable for the data given and that Air America does not have a good overbooking policy (7). A facilitator may pose additional questions to see if students have got sufficient knowledge. For example, he / she can ask students to compute the characteristics for binomial distribution with $\mathrm{n}=126$, to find out the probability that some passengers can not be boarded because of overbooked seats, etc.

Sometimes students need to repeat individual steps to find a new way of problem solving. After each phase students make a report with all the results, and they should receive feedback information.

ICT is a very useful tool for searching information and for statistical analyses. Nevertheless, in the PBL model students use a computer during the instruction for searching new, fresh information and data. They learn how to get proper information from their particular field. Problems are designed in such a way that students realize themselves the importance of a computer.

In the last phase students tackle the most extensive problem in a group. Each group gets a different complex statistical problem. Students use all their prior statistical knowledge for solving it and prepare an oral presentation of the project.

Lectures are designed to help students who are learning through PBL. Lectures provide new information.

PBL is characterised by the following four constitutive elements: problem (1), tutor and facilitator (2), student and skills (3), assessment (4).

\subsection{Problems}

The basic statistics course programmes usually include the following contents (which may, however, appear in a different order): probability calculation (1), random variables (2) probability distributions (3) collection, processing and display of information (4), sampling and calculation of basic statistical parameters of the sample (5), estimation of statistical parameters (6), devising statistical hypotheses (7), regression and correlation (8). We have designed problems to trigger learning in each of the above-mentioned topics of basic statistics. With the first few topics (probability) the students are still in the process of learning how to solve problems by using the 7 Steps Model. At this stage, the facilitator assumes the leading role. With topics (4) and (5) students can draw on sufficient prior knowledge, based on their everyday experience to allow for constructivist problem-solving in a group. The following statistical topics (6-8) systematically rely on the previously described topics; therefore the learning method can be changed. When students address a problem, which was designed to generate 
learning, they are equipped with sufficient prior knowledge to be able to learn as they proceed through problem solving. The facilitator offers immediate feedback information. It should be highlighted, however, so that students gain knowledge through concrete examples, often experimentally, while mathematical derivation of formulas and rules has to be carried out during the lectures, which aim at building the necessary mathematical structure of basic engineering statistics and provide the necessary support for independent learning. The key change lies in the fact that lectures are designed as help offered to students who are learning through PBL. The lectures follow the new method of learning and not the other way round (which is the usual practice in traditional learning, where lectures are followed by practical exercises).

In a traditional way of teaching the teacher usually solves a typical problem. Therefore, even though we dislike it, students' approach tends to be to collect sample solutions. Students just find similar problems and solve them after pattern recognition. If they come across a new type of a problem, they don't know how to start solving it. With PBL, students use a problem to drive learning for a set period of time. Of course they need more time to solve it, but after the process, when they get another problem, they know how to start solving it (Woods, 1995: 4-6, 4-7). The 7 steps give them a good opportunity to handle a new problem. As a result, Slovenian students have a lack of experience in problem solving. Mathematics teachers often notice that students systematically seek pattern recognition in problem solving. When students are faced with a problem where pattern recognition is not possible, because a similar problem has not yet been solved, they give up and do not even start solving it. The 7 Steps Model may not be the shortest way of problem solving, but it is nevertheless one of the possible ways of dealing with a problem in a group.

Statistics, like most of the natural sciences disciplines, is characterised by a hierarchical structure of knowledge. This should be taken into account in the problem-design phase. The first problems are short, simple, and more structured, but gradually the complexity of the problems is increased. At the later stages, however, computer use becomes inevitable, since the students are involved in problem solving, where a considerable amount of data processing is required. At the beginning, two meetings are needed to go through the 7 Steps Model: the first meeting is focused on the aims, and the second meeting is focused on the learning. Subsequently, the time of the problem solving can be increased. An expanded 7 Steps Model with several meetings can be adopted (a meeting on consolidation and a meeting on feedback information can be added). The number of problems is also dependent on the total number of hours available for a subject and on the level of analysis of different topics in basic engineering statistics. The nature of the final problem in the model is close to an engineering project. 
If we follow the taxonomy of problems by Schmidt and Moust (1998), all the problems can be sorted into one of the 4 types of problems:

1. Explanation problem,

2. Strategy problem,

3. Fact-finding problem, and

4. Discussion problem.

An explanation problem is posed to students when they need some new knowledge about a statistical principles, statistical models or theoretical distributions they need for later practical application. An explanation problem is suitable especially at the beginning of the course, when students need some theoretical knowledge. When this kind of problem has been posed, students are often asked to provide explanations to questions like: "Why does this happen? What are the reasons for this situation?"

A strategy problem is useful when the students need to learn some statistical procedures. The emphasis here is not on explanation but on action. The statistical knowledge of engineers is necessary to change unsuitable situations. With this kind of problem we don't ask why the situation is like that, but how to change the situation and what kind of procedure should be followed to do it. Most problems in basic statistics courses are strategy problems. We can pose a strategy problem for almost any basic statistical content. The following short problem is an example, where a teacher can change an explanation problem into a strategy problem, by adding the final sentence:

Survey instruments. A safety manager put together the following survey instrument for a training program (Janicak, 2000: 122-123).

If there is a sentence: »Look at the survey instrument and explain all the potential problems « written at the end of the given instrument in the problem, this is an explanation problem. In this case students are expected to explain the pitfalls in the survey instrument and in similar questionnaires. If the assignment is: »Design your own questionnaire to assess the quality of the course you have attended, distribute it to your colleagues, and analyse the answers « the mentioned problem is a strategy problem. Students change the situation by carrying out their plan.

Strategy problems or explanation problems are very often used in the PBL model for the basic statistics course, while fact-finding or discussion problems are rarely used. The following problem is an example, where the last sentence changes a fact-finding problem into a discussion problem.

Noise of the factory. Study the measurements data given below. If the noise of the factory METAL RAVNE is too high for the 9 houses in the surroundings, a special noise protection wall should be built around the factory. The price for the wall is very high, therefore a major part of production would have to stop and many workers would lose their job. 
If there is a sentence: »Check the regulations for noise and environment protection « at the end of the given problem, this is a fact-finding problem. Students should describe facts and standards useful for the solution of the problem. If the question is: »Do you think a wall should be built or not? « a teacher has designed a discussion problem. Students should describe their beliefs about the two options: to protect the surrounding inhabitants or to protect jobs for many workers

\subsection{Tutors and facilitators in the PBL model}

In our PBL model, groups of 5 students are formed. The groups are not supervised by a tutor, therefore the groups should not be too large. On the other hand, smaller groups would be difficult to manage since the teachers at the University of Ljubljana have approximately 30-40 students per study group for exercises, which means that they have to coordinate the work in six or sometimes even eight PBL groups. The teacher is a facilitator and "flying" tutor at the same time: for a short time the teacher is a tutor in each group, so he /she needs to deal with around 6 groups of students.

Students can choose their own group according to their preferences, which can be an advantage when out-of-class meetings are held. It is also possible to envisage a situation where the teacher forms groups (homogenous or heterogeneous) as regards the (statistics) abilities of the members. In heterogeneous groups weak students perform better and gain more knowledge in statistics, but some very good students may complain that they spend extra time on group cooperation and motivation. Another possibility is to form homogenous groups according to students' field interests, when students can choose from among different branches of studies in their study programme. This can be helpful for the teacher, who can prepare a good problem relevant to a specific field, and for the students who are more motivated for problem solving in the field they are interested in.

The teacher plays the role of a tutor and facilitator simultaneously. At least for some time he / she becomes a member of the group and cooperates with the students. Prior to this students should also be instructed to take over the role of the tutor themselves (Woods, 1995). In the initial stages data search is more or less guided by the facilitator. In the later stages, however, students perform this activity on their own.

\subsection{Students and skills development in the PBL model}

Students will not necessarily possess the basic processing skills needed for the PBL. Asking them to solve a problem does not inevitably mean that they will know how to do it. That is why they should be given the possibility to acquire and 
develop the problem-solving skills and independent-learning skills. These skills should be put to the forefront of instruction, the aims should be determined and the opportunity for practical use of the skill should be provided for. Subsequently, feedback information should be given to the students until the skill has been acquired. While we were designing our model most of our attention and time was devoted to the development of problem-solving and independent-learning skills.

According to the 7 Steps Model the problem-solving skills are highlighted at the beginning of our model cycle. Students are developing these skills in the introductory phase of the PBL while working on the probability calculus and probability distributions, i.e. mathematical topics.

In the field of engineering, modern technology is very important for the development of independent-learning skills such as: independent searching for relevant information, independent processing of information, cognitive integration of new and old information, and communication of new information to other people. ICT plays a crucial role in this respect: electronic data search of different web sites, electronic data processing with data display methods (tables, graphs, functions, diagrams, etc.), basic (statistical) data calculation (e.g. calculation of functions with given data, exclusion and selection of data with specific characteristics, data calculation of basic statistical characteristics of a population or a sample, etc.) and advanced statistical calculation (testing hypothesis, regression, etc.).

In one of the final problems we pose to the group, engineering students need to apply almost all of their basic statistical knowledge and combine quality problemsolving and independent-learning skills.

Computer related risks at workplace. $\mathrm{PC}$ has become an inevitable tool in many workplaces. What are the requirements for a workplace with display screen equipment and what are the risks? What are the trends in the use of PC in Slovene firms? Does the eyesight of an employee at FCCT depend on the number of hours spent in front of a display screen?

This problem consists of a set of questions. The aim of the first question is to lead the students to relate the problem to the suitable field of safety engineering. Students start a discussion about common safety risks in computer use. They will probably search for additional information on the internet (standards and requirements for a workplace with display screen equipment). The answer to the second question will give the group an insight into how many workers in Slovenia deal with computers. Students need to calculate a correlation coefficient and a regression for the data found on the internet or in some magazines. The last question is the most important. Students need to provide data and information by themselves. They must select a sample from the population, define variables needed for statistical analysis, and prepare a questionnaire to get adequate data for the sample. Then, they need to set up a statistical hypothesis and analyze the data with a suitable testing procedure. After the correct interpretation of the test, they can answer the main question in the problem. They have to think critically about the results and interpret the situation. The computer is very important for quality search as well as for presenting tables, histograms, regression graphs, for statistical 
calculations and for statistical analysis. The computer is also used to prepare a written report and presentation.

For the purposes of the particular statistics course where this PBL model was verified it was decided that EXCEL software package would be presented to the students (Triola, 2001), because this programme is largely available also in engineering professional environments. Students should be instructed how to use the computer. They should also be warned that a computer can calculate many different things, while they are expected to know what exactly the calculated value means and which calculations make sense.

In our teaching situation the skills of successful cooperative learning and teamwork as well as self-assessment had been developed in other courses carried out prior to the course of basic engineering statistics. In the verification phase these skills were reinforced and further developed within the model cycle. Due to a reduced number of hours the self-assessment skill was not allotted enough time. The students' self-assessment grades were carefully studied by the teachers, but were not accounted for in the final grade.

\subsection{Assessment in the PBL model}

In our PBL model we use the outcome-oriented assessment methods (1) and process-oriented assessment methods (2) (Swanson, Case, and Van der Vleuten, 1998).

In outcome-oriented assessment methods (1) the knowledge, acquired in a constructivist manner and the student's competences in independent reasoning and problem solving are assessed, rather than the ability to learn facts and principles. Since good statistical knowledge, which is based on mathematical pillars, requires a step-by-step approach to understanding and expansion of knowledge, the students' development is continuously checked and immediate feedback is provided on the correct results, on the material learned, and on the input of the individual student in comparison with other students. In our model a multiple choice test is used to assess the basic statistic knowledge, required for correct statistical reasoning, and the results of this test account for $25 \%$ of the total grade.

Process-oriented assessment methods (2) include the assessment of the student's independent-learning skills and problem-solving skills. To enable the students to gain a better insight into these skills within the new model of learning, we ask students to assess themselves. This helps them to identify their strong points and weak points. As the groups were not tutor guided, self-assessment and peer-assessment constitute a useful impulse and interior motivation for the groups, and also develop the students' peer-and self-assessment skills, which is important for their professional life. Both assessment results are an important indicator of the student's progress in the learning process and of the student's personal 
characteristics (e.g. an extremely negative self-image, or an extremely positive self-image). In our model, students complete a self-assessment questionnaire before and after the PBL, while the peer-assessment is handed in after the end of the cycle. We opted for secret assessment, however we did allow for the possibility of naming the members. But we did not include these results in students' final grade because we did not teach these skills.

Three final outputs are used for assessing both: knowledge and skills (Ronis, 2001): a portfolio, which includes the student's assignments, pointed to the overall input of the student, and to his /her personal development and solutions of all problems; a written report, which includes the description of the overall course of problem-solving for the final problem, the description of the work, the difficulties, the interpretation and the conclusions; an oral presentation, which is designed as a public presentation of the final problem (Figure 1).

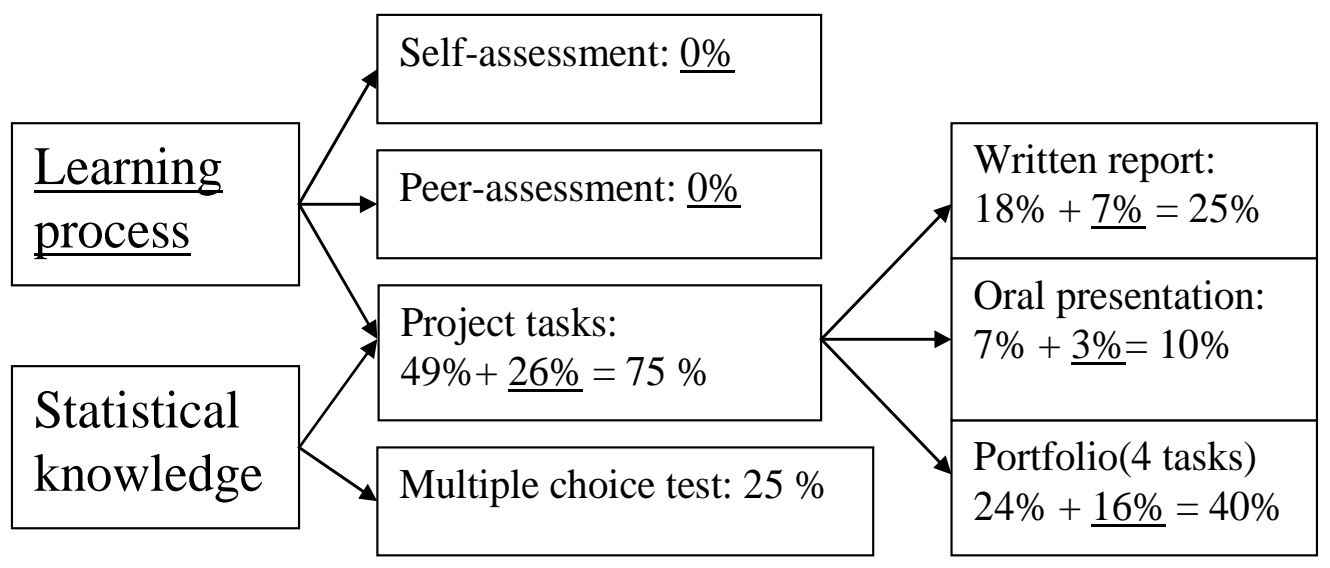

Figure 1: Assessment in the PBL model with impacts on final grade in percentages.

An individual contribution by each member of a group is especially delicate in group learning. We organize assessment in such a way that the individual student's statistical knowledge and contribution to the group are measured. A multiple choice test measures an individual's basic statistical knowledge. Some problems are organized in such a way that an individual calculation of each member of the group is demanded in addition to a group written report. In the last problem, which is the most extensive, each student prepares an oral presentation and a defence of the work. There are also a peer assessment and a portfolio which indicate effort and contribution to the group work of the individual student. Therefore, if one student does the work for another member, he /she has to teach this member how to defend the work and new knowledge.

\section{Verification of the PBL model}

In order to find out whether the PBL model in teaching basic engineering statistics yields a better quality of instruction and advantages over the traditional instruction 
the pedagogical experiment was carried out. The experiment was conducted with a group of students of the Department of technical safety at the Faculty of chemistry and chemical technology (DTS FCCT) at University of Ljubljana, Slovenia. During the time of the curriculum reform this department was ready to integrate a certain number of subjects and to organise a PBL programme for a randomly chosen group of students. The students of DTS FCCT, University of Ljubljana, regularly enrolled in the second year of the study programme, were randomly distributed into two groups: the experimental group (EG) and the control group (CG). There were 38 students in each group. Students in EG were offered a PBL instruction 2 hours per week during the second semester, while their colleagues in the CG were learning basic engineering statistics in the traditional way at the same time.

The statistical analysis of the pre-test and the post-test results showed that the students, who had been learning basic engineering statistics with PBL, acquired sufficient basic statistical knowledge, when we compared them to the results of the students who had been learning with a traditional model of instruction. Moreover, the PBL students performed better in simple problem-based tasks. In this respect, the quality of the acquired knowledge was even better in the EG than in the CG.

The statistical analysis of project reports from the field of statistics in safety science (the problem in the last phase of the PBL model), yielded results which demonstrate that the PBL students were better able to solve complex problems, and that they could apply their theoretical knowledge more efficiently than the students who were learning with the traditional method of instruction. The EG students outperformed their CG peers in the number of oral reports and in the achievement scores of problem tasks in the final test. We did, however, have some reservations, when comparing the problem solutions and the assessment results of the project work in the $\mathrm{CG}$ and in the EG.

The results of the questionnaire on the students' attitude towards instruction indicate that the students of both groups had a positive attitude towards the instruction of basic engineering statistics. It was shown, however, that the PBL students as compared with their peers in the traditional instruction knew significantly better what kind of knowledge they were expected to show, and that the PBL students scored significantly better in the level of progress achieved in their communication, administrative, and public speaking skills. We concluded that the absence of statistically significant differences in other attitudes and scores can be explained by several factors: a slightly changed method of traditional instruction because of the constraints of the experiment; an inadequately chosen time for completion of the questionnaire; overburdened weaker students; and the use of a previously unpiloted questionnaire.

The PBL in basic engineering statistics significantly improved the students' competences in planning, organisation of learning, data search for specific information, skills of data transformation and data display. All these independent- 
learning skills and life-long learning skills have become essential in the rapidly developing world of science.

Finally, it was shown that the students had positive attitudes towards learning in small groups and towards the use of the computer in statistics. Details of previous analyses can be found in Drobnič Vidic (2005).

We are aware that the data obtained by the method of choosing a particular study program, even though random selection of students has been applied, can not constitute a conclusive proof that the PBL model is better than the traditional one for basic engineering statistics courses in general, but in pedagogical research it is difficult to obtain a proper random sample from the student population. Nevertheless the presented experiment with random selection of students of a particular study program at University of Ljubljana can encourage us to use the PBL model with other students of the basic engineering statistics course.

\section{Conclusions}

The PBL model is a suitable and effective pedagogical strategy for learning basic engineering statistics because of facilitators' hard work (1) and students' motivation (2).

(1) The facilitator in PBL works hard (preparing suitable problems, giving feedback after every problem, doing alternative assessment, etc.). The effort and devotion of the teacher are crucial for PBL. On the one hand, even a well-planned PBL instruction cannot succeed if the teacher is not motivated. On the other hand, a traditional instruction can be very successful if the teacher conducts it well, if it generates a cognitively integrated and constructivist learning, and if it provides conditions for student identification. A PBL setting offers conditions for the constructivist acquisition of knowledge, for student-centred learning, and for the development of skills, which are needed for effective professional functioning of the students. Whether and how much the students will profit from these conditions depends on the teacher.

(2) Students in PBL have a strong motivation to work with real-life or professionally relevant problems, where they can apply statistics knowledge. A well designed PBL problem has the adequate difficulty and requires the adequate amount of prior knowledge; consequently it attracts students to try to solve it and to identify learning objectives. Setting up their own learning objectives is another motivation for the students to learn new content more effectively. A problembased curriculum offers a flexible framework, with the possibility to leave out some contents and to provide more detailed information and deeper understanding of a given content. Thus, the main goal of studying is not to acquire as much information as possible, but to teach students how to think, to give them the most useful knowledge for further learning and provide conditions in which students will develop some competences for independent learning. 
Nevertheless, the PBL would be even more effective in basic engineering statistics if we had a tutor for each group, better equipment, and if this kind of instruction were applied also with some other subjects. Thus, less effort would be put in the process of PBL introduction in basic engineering statistics. The 7 Steps Model, the self-assessment and similar process tasks would be less timeconsuming; the quality of the work in the basic engineering statistics would be enhanced.

Engineering students need to acquire basic statistics knowledge, which they will later successfully apply at work as well as independent-learning skills, group skills, and ICT skills, very important in their professional careers. In the fields where students' applicable knowledge and all mentioned skills are also important, this PBL model for teaching basic engineering statistics may also be suitable for them.

\section{References}

[1] Barr, R.B. and Tagg, J. (1995): From teaching to learning: A new paradigm for undergraduate education. Change Magazin, 27 13-25.

[2] Bland, JM. (2004): Teaching statistics to medical students using problembased learning: the Australian experience. BMC Medical Education, 4. [Electronic version] (http://www-users.york.ac.uk/ mb55/talks/ozpbl.htm ).

[3] Boud, D. and Feletti, G.I. (1998): The Challenge of Problem-Based Learning (2nd ed.). London: Kogan Page.

[4] Boyle, C.R. (1999): A Problem-based learning approach to teaching biostatistics. Journal of Statistics Education, 7 [Electronic version] (http://www.amstat.org/publications/jse/secure/v7n1/boyle.cfm ).

[5] Cannon, R. and Newble, D. (2000): A Handbook for Teachers in Universities and Colleges, A Guide to Improving Teaching Methods. London: Kogan Page.

[6] Cobb, G.W. (1993). Reconsidering statistics education: A national science foundation conference. Journal of Statistics Education, 1 [Electronic version] (http://www.amstat.org/publications/jse/v1n1/cobb.html).

[7] Colliver, J.A. (2000): Effectiveness of problem-based learning curricula: research and theory. Academic Medicine, 75, 259-266.

[8] David, T., Patel, L., Burdett, K., and Rangachari, P. (1999): Problem-Based Learning in Medicine, a Practical Guide for Students and Teachers. London: Royal Society of Medicine Press.

[9] Dolmans, D. and Snellen-Balendong, H. (2000): Problem-Based Medical Dducation: Problem Construction. Maastricht: Department of educational development and research. 
[10] Driessen, E. and Van der Vleuten, C.P.M. (2000): Matching student assessment to problem-based learning: lessons from experience in a law faculty. Studies in Continuing Education, 22, 235-248.

[11] Drobnič Vidic, A. (2003): Statistika in matematika v šoli. Sodobna pedagogika, 54, 168-183.

[12] Drobnič Vidic, A. (2005): Problemsko zasnovan študij pri proučevanju inženirske statistike: doktorska disertacija. Ljubljana: Filozofska fakulteta.

[13] Eitel, F. and Gijselaers, W. (Eds.) (1997): Problem-Based Learning: Theory, Practice and Research. Zeitschrift für Hochschuldidaktik, Innsbruck: Studien-Verlag.

[14] Fillebrown, S. (1994): Using projects in an elementary statistics course for non-science majors. Journal of Statistics Education, 2 [Electronic version] (http://www.amstat.org/publications/jse/v2n2/fillebrown.html) .

[15] Garfield, J. (1993): Teaching statistics using small-group cooperative learning. Journal of Statistics Education, 1 [Electronic version] (http://www.amstat.org/publications/jse/v1n1/garfield.html) .

[16] Gijselaers, W.H. and Schmidt, H.G. (1990): Development and evaluation of a casual model of problem-based learning. In A.M. Nooman, H.G. Schmidt and E.S. Ezzat (Eds.): Innovation in Medicine Education: An evolution of its Present Status (95-113). New York: Springer.

[17] Hendry, G.D., Frommer, M., and Walker, R.A. (1999): Constructivism and problem-based learning. Journal of Further and Higher Education, 23, 359371.

[18] Janicak, C.A. (2000): Applied Statistics in Occupational Safety and Health. Maryland: Government Institutes Rockville.

[19] Japelj B., Magajna Z., Drobnič Vidic, A., Žakelj, A., Čuček, M., Brečko, B., Perat, Z., Makarovič, M., and Klokočovnik, A. (2002): Tretja mednarodna raziskava matematike in naravoslovja IEA TIMSS in druga mednarodna raziskava o informacijski tehnologiji $\mathrm{v}$ izobraževanju IEA sites ter vključevanje izsledkov v slovenski izobraževalni sistem: poročilo projekta CRP 1999-2002. Ljubljana: Center IEA raziskave, Pedagoški inštitut.

[20] Lovie-Kitchin, J. (2001): Reflecting on assessment. In P. Schwartz, S. Mennin and G. Webb (Eds.): Problem-Based Learning: Case Studies, Experience and Practice, Case Studies of Teaching in Higher Education, 149-155. London: Kogan Page.

[21] Mackisack, M. (1994): What is the use of experiments conducted by statistics students. Journal of Statistics Education, 2 [Electronic version] (http://www.amstat.org/publications/jse/v2n1/mackisack.html).

[22] Magel, R.C. (1998): Using cooperative learning in a large introductory statistics class. Journal of Statistics Education, 6 [Electronic version] (http://www.amstat.org/publications/jse/v6n3/magel.html). 
[23] Mendoza, P.L. (ed.) (1998): Proceedings of the Fifth International Conference on Teaching of Statistics (ICOTS5). Singapur: The National organizing committee.

[24] Moore, D.S. and McCabe, G.P. (2003): Introduction to the Practice of Statistics. New York: W.H. Freeman.

[25] Moust, J.H.C., Bouhuijs, P.A.J., and Schmidt, H.G. (2001): Problem-Based Learning: A Student Guide. Groningen: Wolters-Noordhoff.

[26] Perrenet, J.C., Bouhuijs, P.A.J., and Smits, J.G.M.M. (2000): The suitability of problem-based learning for engineering education: theory and practice. Teaching for Higher Education, 5, 345-358.

[27] Ronis, D. (2001): Problem-Based Learning for Math and Science: Integrating Inquiry and Internet. Arlington Heights: SkyLight Training and Publishing company.

[28] Rossman, A.J., Chance, B.L., C., Lock, R.H., and von Oehsen, B. (2002): Workshop Statistics: Discovery with Data. Guide for Instructors. http://www.keycollege.com/ws/Discovery_with_Data/InstructorGuide.html

[29] Scheaffer, R.L., Gnanadesikan, M., Watkins, A., and Witmer, J.A. (1996): Activity-Based Statistics. New York: Springer Verlag.

[30] Schmidt, H.G. and Moust, J.H.C. (1998): A taxonomy of problems used in problem-based curricula. In J. Van Marrienboer and G. Koerkerke (Eds.): Instructional Design for Problem-Based Learning, Proceedings of the Third Workshop of the EARLI SIG Instructional Design, 3-12. University of Maastricht.

[31] Schmidt, H.G. and Moust, J.H.C. (2000): Factors affecting small-group learning: a review of research. In D.H. Evensen and C.E. Hmelo (Eds.): Problem-Based Learning: a Research Perspective on Learning Interactions, 19-51. New York: Lawrence Erlbaum Associates.

[32] Schwanson, D., Case, S., and Van der Vleuten, C. (1998): Strategies for student assassment. In D. Boud and G.I. Feletti (Eds.): The Challenge of Problem-Based Learning, 269-282. London: Kogan Page.

[33] Snellen-Balendong, H. (1993): Rationale underlying the design of a problembased curriculum. In P.A.J. Bouhuijs, H.G. Schmidt and H.J.M. Van Berkel H.J.M. (Eds.): Problem Base-Learning as an Educational Strategy, 69-78. Maastricht: Network publications.

[34] Staver, J.R. (1998): Constructivism: Sound theory for explicating the practice of science and science teaching, Journal of Research in Science Teaching 35, 501-520.

[35] Triola, M.F. (2001): Elementary Statistics using EXCEL. Addison-Wesley Longman.

[36] Vermunt, J.D. and Verloop, N. (1999): Congruence and friction between learning and teaching. Learning and Instruction, 9, 257-280. 
[37] Wilkerson, L. and Hundert, E. (1998): Becoming a problem-based tutor: increasing self-awareness through faculty development. In D. Boud and G.I. Feletti (Eds.): The Challenge of Problem-Based Learning, 160-172. London: Kogan Page.

[38] Wood, G.R. and Wasimi, S.A. (1998): Transforming first year university statistics teaching. In P.L. Mendoza (Ed.): Proceedings of the Fifth international conference on teaching of statistics (ICOTS5), 1, 167-172. Singapur: The National Organizing Committee.

[39] Woods, D.R. (1994): Problem-Based Learning: How to Gain the most From $P B L$. Hamilton: McMaster University.

[40] Woods, D.R. (1995): Problem-Based Learning: Helping your Students Gain the Most from PBL. www.chemeng.mcmaster.ca/pbl/pbl.htm. 